\title{
ESTRANHOS NO NINHO: JUVENTUDE, CONSUMO E ESCOLA
}

\section{NESTLING IN THE NEST: YOUTH, CONSUMPTION AND SCHOOL}

\author{
SOUZA, Pedro Henrique de Oliveira de ${ }^{1}$ \\ LIMA, Maria Jacqueline Girão Soares de ${ }^{2}$
}

\begin{abstract}
RESUMO
Apresentamos um projeto desenvolvido por um grupo de pesquisa e extensão em educação ambiental de uma universidade pública carioca, que focalizou a relação de jovens com o consumo e as mediações realizadas pela escola. A partir de referenciais teóricos críticos e pós críticos sobre consumo e juventude, analisamos entrevistas de tipo grupo focal com estudantes, gestores, técnicos e docentes de uma escola pública federal do Rio de Janeiro. Os entrevistados expuseram suas visões a respeito do consumo entre jovens, relataram atividades desenvolvidas na escola e revelaram seus sonhos e práticas de consumo. Os dados produzidos geraram reflexões sobre o aspecto geracional da problemática do consumo, as identidades juvenis e as ações da escola nesse contexto. Em diálogo com pesquisas sobre juventude, defendemos que os conflitos em torno da relação juventude/consumo tem relação com a dificuldade de se considerar os jovens como sujeitos sociais, capazes de interpretar e dar sentido ao mundo.
\end{abstract}

PalaVras-Chave: Juventude; Identidade; Consumo; Escola.

\section{ABSTRACT}

We present a project developed by a group of research and extension in environmental education of a public university in Rio de Janeiro, that focused on the relationship of young people with consumption and mediations carried out by the school. Based on critical and post critical references on consumption and youth, we analyzed interviews with students, managers, technicians and teachers from a federal public school in Rio de Janeiro. The interviewees exposed their views on consumption among youth, reported school activities and revealed their dreams and consumption practices. The data produced generated reflections on the generational aspect of the consumption problem, the juvenile identities and the actions of the school in this context. In dialogue with youth research, we argue that the conflicts around the youth/consumption relationship are related to the difficulty of considering young people as social subjects capable of interpreting and giving meaning to the world.

KeYWORDS: Youth; Identity; Consumption; School.

\footnotetext{
${ }^{1}$ Bolsista de iniciação científica; Instituto de Biologia; Universidade Federal do Rio de Janeiro. e-mail: pedrohdesouza93@gmail.com

${ }^{2}$ Doutora em Educação; Faculdade de Educação; Universidade Federal do Rio de Janeiro. e-mail: giraojac@gmail.com
} 


\section{INTRODUÇÃO}

Nas duas últimas décadas, pesquisas e políticas públicas relacionadas à juventude se intensificaram no Brasil e no mundo. Leis, propostas e iniciativas dos mais diferentes tipos e setores se debruçam sobre as realidades dos jovens, vislumbrando possíveis cenários e caminhos frente às principais questões, supostamente, enfrentadas por eles. Em nosso país, foram criados nesse período o Conselho Nacional de Juventude, a Secretaria Nacional de Juventude e o Sistema Nacional de Juventude, que culminaram em projetos de lei e políticas públicas tais como o Plano Nacional de Juventude, o (novo) Plano Juventude Viva e a Política Nacional de Juventude ${ }^{3}$ (ABRAMOVAY e CASTRO, 2015). Estas autoras utilizam o estudo nacional Ser jovem no Brasil hoje para discutir os perfis dos jovens brasileiros nessas políticas públicas voltadas à juventude, cujas representações sobre os jovens oscilam de "ameaça à paz social, como seres desviantes que precisam ser controlados ou como seres em formação que necessitam de auxílio para se desenvolverem, sob um viés assistencialista" (p.20).

Juventude, enquanto condição biopsicológica e social ${ }^{4}$, e não apenas etária, é tema de estudos que problematizam tanto os limites das definições apresentadas quanto os desafios e propostas de enfrentamento das principais temáticas juvenis. Autores como Dayrell (2003) e Pais (2003), usam o termo juventudes, para ressaltar o caráter plural e os múltiplos fatores envolvidos na construção e constituição (das identidades) dos jovens. No entanto, em diversos documentos oficiais de governos e organizações internacionais, ainda se nota a centralidade do fator etário nas sínteses sobre a(s) juventude(s), como por exemplo, em nossa Política Nacional de Juventude:

a juventude é uma condição social parametrizada por uma faixa etária, que no Brasil congrega cidadãos e cidadãs com idade compreendida entre 15 e 29 anos. Nesse caso podem ser considerados jovens os adolescentes-jovens (15-17 anos), os jovens-jovens (18-24 anos) e os jovens-adultos (25-29 anos) (BRASIL, 2006, p. 5).

Essa "condição social" manifesta na definição anterior traz um importante ponto para se discutir a juventude: se ela é uma condição social, que fatores estão construindo, influenciando, reafirmando, potencializando ou limitando o viver desses jovens? Além disso, o que tem sido feito para ressignificar a condição juvenil nos dias de hoje, onde cada vez mais somos influenciados por uma ideologia neoliberal e meritocrática, materializada nos discursos e práticas de políticas públicas

\footnotetext{
3 Outros projetos são: ID Jovem, ProJovem, Programa Nacional de Acesso ao Ensino Técnico e Emprego (Pronatec), Programa Universidade para Todos (PROUNI), Observatório Participativo da Juventude (Participatório), Programa de Fortalecimento da Autonomia Econômica e Social da Juventude Rural (Pajur), Programa Nacional de Fortalecimento da Agricultura Familiar (Pronaf Jovem).

${ }^{4}$ Ver Bourdieu (1983), Abramovay e Castro (2006 e 2015), Costa (2009) e outros.
} 
governamentais e em várias relações cotidianas? Quais são as consequências desse processo para os jovens?

Uma forma potente de se olhar para a realidade em que vivemos - e como ela influencia as juventudes - é através da observação das formas como os jovens se relacionam com o consumo (COSTA, 2009). Abramovay e Castro (2015) identificaram cinco desafios/categorias para o reconhecimento dos direitos humanos e para políticas e potencialidades dos jovens: um deles, que chamaram de "Mundo Espetáculo", considera que os jovens são "sujeitos de uma sociedade de consumo ostentatória, cujo principal traço é suscitar aspirações que, muitas vezes, deságuam em frustrações, porque irrealizáveis para a grande maioria (...)" (p.14). Segundo essa ideia, os jovens "transitam no seio de uma arquitetura social cuja desigualdade e o acirramento das diferenças constituem algumas de suas faces mais visíveis" (ABRAMOVAY e CASTRO, 2015, p.22). É neste contexto que esta pesquisa, que busca compreender e problematizar as diversas formas de relação dos jovens com 0 consumo, se insere.

Pertencemos a um grupo que desenvolve ações de ensino, pesquisa e extensão em espaços públicos (universidades, escolas, parques etc.) do Rio de Janeiro, junto a estudantes, docentes e público em geral. Produzimos materiais didáticos, cursos e oficinas sobre temáticas socioambientais como consumo, sustentabilidade, lixo, alimentação e agricultura numa perspectiva crítica, em diálogo com os saberes e as demandas dos sujeitos e/ou instituições com os quais trabalhamos. Em atividades de extensão realizadas com um grupo de docentes da Secretaria Municipal de Educação do Rio de Janeiro, observamos uma forte presença de discursos que estabelecem relação linear entre o desinteresse dos jovens pela escola e o interesse por bens de consumo, tais como eletrônicos e roupas de marca. Esse é um dentre muitos discursos que engessam identidades juvenis em consumistas, individualistas, alienadas, problemáticas e outras, sem oferecer alternativa para lidar com os conflitos e dificuldades enfrentados pelos jovens e pelas escolas.

Partindo deste incômodo, na primeira parte desta pesquisa que teve início em 2014, buscamos investigar e problematizar hábitos e percepções sobre consumo de jovens a partir de imagens, vídeos e textos utilizados em uma oficina desenvolvida com estudantes de três escolas públicas. Os debates culminaram nas perguntas: "Qual é o seu sonho de consumo?" e "Qual é o seu sonho que não envolve consumo?". As respostas às perguntas e debates nos mobilizaram para desenvolver a segunda fase da pesquisa, que se faz parcialmente presente neste artigo, ampliando nossas investigações sobre a relação juventude/consumo e as reflexões sobre a mediação exercida pela escola. A pesquisa faz parte de um projeto de iniciação científica que busca compreender as relações entre a juventude, 0 consumo e a escola e está sendo realizada com docentes, discentes e gestores de duas escolas públicas: uma federal e uma estadual. 
DOI: $10.12957 /$ e-mosaicos.2018.34194

Não poderíamos, no espaço deste artigo, esgotar as questões que se materializam no viver dos jovens em nossa sociedade - ocidental, contemporânea, capitalista e consumista, mas sim, apresentar um recorte que nos possibilite refletir de/sobre um "outro lugar". O objetivo desta pesquisa é compreender a relação da juventude com o consumo, que se configura hoje como "o centro organizador da ordem social, política, econômica e cultural do presente," (COSTA, 2009, p.35) e as mediações realizadas pela/na escola. Partindo desse "lugar", realizaremos nas próximas seções uma reflexão sobre a pesquisa de nosso grupo, apresentando a primeira etapa (realizada em 2014 com três escolas municipais) e a fase atual, desenvolvida em duas escolas públicas: uma federal e uma estadual do Rio de Janeiro. Inicialmente, os termos juventude e consumo serão discutidos à luz de autores que estudam cada campo separadamente; posteriormente, nos aprofundaremos nas relações que se estabelecem entre essas 'palavras'.

\section{CONCEITUAÇÕES E OS CRESCENTES INVESTIMENTOS NA PARCELA JOVEM DA POPULAÇÃo BRASILEIRA}

(...) a juventude, por definição, é uma construção social, ou seja, a produção de uma determinada sociedade originada a partir das múltiplas formas como ela vê os jovens, produção na qual se conjugam, entre outros fatores, estereótipos, momentos históricos, múltiplas referências, além de diferentes e diversificadas situações de classe, gênero, etnia, grupo etc. (ESTEVES e ABRAMOVAY, 2007, p. 21).

A definição acima suscita reflexões acerca do entendimento sobre a juventude e a multiplicidade de conceitos e fatores que influenciam nosso ideário do que é ser jovem. Bourdieu (1983) elenca conceituações sobre a adolescência/juventude em determinadas sociedades para expor o caráter mutável do(s) termo(s) ao longo do tempo. $O$ pensador francês afirma ainda que:

(...) a idade é um dado biológico socialmente manipulado e manipulável; e que o fato de falar dos jovens como se fossem uma unidade social, um grupo constituído, dotado de interesses comuns, e relacionar estes interesses a uma idade definida biologicamente já constitui uma manipulação evidente (BOURDIEU, 1983, p. 2).

A idade biológica é um marcador bastante utilizado na conceituação de juventude, apesar de diferenças nos limites dessas classificações (etárias), sobretudo naquelas institucionais, utilizadas em pesquisas, projetos de lei e iniciativas do terceiro setor. Indivíduos de quinze a vinte e quatro anos completos integram a 
categoria "juventude" para a Organização das Nações Unidas para a Educação, a Ciência e a Cultura (UNESCO) e o Instituto Brasileiro de Geografia e Estatística (IBGE), enquanto que o Governo Federal (Secretaria Nacional de Juventude e legislativo) categoriza como jovens os indivíduos de quinze a vinte e nove anos completos. Em contextos específicos, sobretudo relacionados a questões judiciais e/ou legislativas ${ }^{5}$, adolescentes de dez a catorze também são considerados jovens pelo governo brasileiro.

Bourdieu (1983) e Pais (2003) discorrem sobre a construção social das noções de juventude e velhice, impostas por padrões hegemônicos do mundo adulto e que estabelecem uma divisão de poder. Reconhecida pelo senso comum, a atribuição de certa "irresponsabilidade provisória" aos adolescentes os faz serem lidos ora como adultos ora como crianças, dependendo do contexto. É nesta "existência separada" que o jovem é socialmente colocado, por vezes, fora do jogo. Rocha \& Pereira (2009), em livro que discute questões vinculadas à juventude, consumo, novas tecnologias, luxo e comunicação, relativizam algumas das afirmações de Bourdieu pois "em algumas esferas da sociedade, a adolescência parece estar dentro e, mais ainda, no comando do jogo". Caso contrário, não se despenderiam tantos esforços e investimentos para compreender os adolescentes, que na visão deles, "passam a orientar diversos saberes e, principalmente, mercados, como os da moda, da tecnologia e do entretenimento" (BOURDIEU, 1983, p. 16).

O censo GIFE (2016) traz um balanço dos investimentos empregados pela iniciativa privada no que tange à juventude, pois, entre as empresas entrevistadas, as principais áreas de interesse foram: educação (84\%) e formação de jovens para o mercado de trabalho e/ou para cidadania (60\%). Os dados corroboram a tese de uma crescente inserção do setor privado na esfera pública, sobretudo na educação brasileira ${ }^{6}$.

\section{CULTURA DO CONSUMO: CONCEITUAÇõES E INFLUÊNCIA NO VIVER CONTEMPORÂNEO NO BRASIL}

Costa (2009) ressalta que nossa educação é voltada para uma vida baseada no consumo. Essa visão decorre da influência da sociedade de consumidores (BAUMAN, 2008) na cultura e demais aspectos da vida contemporânea, em que o consumo exerce um papel de identificador social (COSTA, 2009). Fontenele (2017) destaca a importância da cultura do consumo - aqui entendida como uma outra face da sociedade de consumidores - nas relações humanas, partindo de suas origens. Trazemos, para este debate, alguns elementos que nos indicam como se deu a consolidação da cultura do consumo nas sociedades ocidentais e orientais.

\footnotetext{
${ }^{5}$ Alguns exemplos são: trabalho infantil, exploração sexual e algumas questões ligadas aos jovens residentes em áreas rurais e/ou de extrema pobreza.

${ }^{6}$ Maiores informações em Leher et al (2017) e Gawryszewski et al (2017).
} 
O consumo, na forma como o conhecemos atualmente, se origina após as revoluções francesa e industrial, que consolidaram Inglaterra, Alemanha e França como potências econômicas globais nos séculos XVIII e XIX (FONTENELE, 2017). A versão contemporânea do consumo surge na passagem da sociedade de produtores à sociedade de consumidores, do consumo ao consumismo, dos bens duráveis à obsolescência dos bens (BAUMAN, 2008) e possui forte influência do American way of life, característico da sociedade estadunidense desde o século passado. Essas mudanças impactaram diretamente a construção do homem contemporâneo, criando uma sociedade com indivíduos que possuem desejos e relações efêmeras e fluidas, além de um ambiente que convida "os cidadãos contemporâneos ao deleite consumista, ou melhor, ao desempenho de um papel social que privilegia a satisfação instantânea em detrimento do adiamento/postergação dos desejos" (OLIVEIRA e TOMAZETTI, 2012, p.190). No entanto, falas de nossos entrevistados, mais à frente, irão mostrar a existência de iniciativas contraculturais que já se manifestam no discurso e na práxis dos jovens em relação aos seus sonhos de consumo (BASTOS et al, 2015).

O aspecto central da cultura do consumo, o valor da imagem, ainda que evidente desde seus primórdios, ganhou notoriedade para Fontenele (2017) apenas no que a autora considera a "segunda fase da cultura do consumo"", surgida após segunda guerra mundial. A ideia era vender um produto que fora produzido para atender os desejos (in)conscientes do consumidor de ser outra pessoa, a que consome aquele produto, à luz da influência do marketing, psicanálise, psicologia, desenvolvimento tecnológico e mudanças de ordem econômica, social, cultural e política que ocorreram em países ocidentais desde então. 0 homem tornou-se também um produto a ser anunciado, consumido, formando uma "subjetividade consumidora de mercadorias (...) para além da ideia da "mera utilidade' do objeto" (p.58).

Marcas, produtos, mídias e publicidade se entrelaçam e influenciam desejos e hábitos de consumo em nossa sociedade, tendo na infância e juventude um importante mercado consumidor, pois

(...) um indivíduo se sente membro de um grupo mesmo estando sozinho. E quando planeja realizar algum ato de compra, esse indivíduo o faz não com base em seu único e próprio julgamento, mas a partir de uma miscelânea de imagens e discursos impressos em sua psique por influências externas que, muitas vezes inconscientemente, comandam suas ações (BERNAYS, 1928 apud FONTENELE, 2017, p. 40-41).

\footnotetext{
${ }^{7}$ Em linhas gerais, Fontenele (2017) aponta que a primeira fase da cultura do consumo investiu na produção do que é o consumidor. Já na segunda fase, a ideia é relacionar cultura e economia para modelagem dos sujeitos via imagens e marcas.
} 


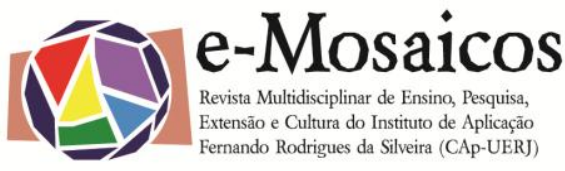

DOI: $10.12957 /$ e-mosaicos.2018.34194

Abramovay e Castro (2015) ressaltam que ser jovem também está associado a "uma estética desejada pela maioria, um valor simbólico associado à beleza, o que faz com que a sociedade possa comercializar os seus diversos atributos, em forma de mercadorias, em que a imagem se compra e se vende, intervém no mercado do desejo como veículo de distinção e legitimidade" (MARGULIS e URRESTI, 1996 apud ABRAMOVAY e CASTRO, 2015, p.2). Desse modo, nos indagamos como e sob que interesses essa cultura consumista está presente no cotidiano dos jovens, além de questionamentos referentes à pluralidade de discursos e formas identitárias juvenis. Buscamos, a partir dessas e de outras perguntas, refletir sobre a relação juventude/consumo e os possíveis papéis de mediação da escola.

Em tema que dialoga bastante com a nossa pesquisa, Costa (2009) no capítulo "Há estranhos nas escolas", investiga "a entrada e presença da cultura pósmoderna na escola e sua produtividade na constituição de sujeitos e na conformação das práticas pedagógicas" (COSTA, 2009, p. 90), sobretudo nas escolas públicas de periferias urbanas. Esses "estranhos" são crianças e jovens que parecem destoar da ordem escolar, pois "ostentam de forma tão visível e gritante as marcas da espetacularização da mídia e do consumo que destoam dos ambientes escolares discretos e ordenados; parece que não pertencem à cena pedagógica, que estragam o quadro" (COSTA, 2009, p. 90). Como destaca Costa (2009):

Para que nenhum consumidor seja desperdiçado, há versões de produtos adaptadas ao perfil de distintos grupos de sujeitos. As práticas do capitalismo neoliberal dirigidas à promoção do consumo materializam-se em estratégias extremamente sofisticadas, caprichosas, minuciosas, e têm na mídia seu território mais pródigo (...) Os 'estranhos' de nossas escolas públicas não estão desqualificados para os atos de compra, já que o mercado é caprichoso, extremamente elástico e atento às diferenças (de interesses, de poder aquisitivo, de grupo social etc.). Tampouco se pode dizer que se dediquem compulsivamente ao descarte. Talvez se possa afirmar que se dedicam à fruição, extraindo da posse possível, fugaz ou não, tudo o que ela pode oferecer, quase como fulguração. Pode-se dizer que esses alunos e alunas são, antes de tudo, consumidores-simulacro constituídos em um trânsito constante entre o 'desejo de ter' e a possibilidade de 'parecer ter' (Costa, 2009, p. 9192).

\section{A PESQUisA e OS RESULTADOS}

Nossa pesquisa investigou qualitativamente uma escola federal da rede pública localizada na zona sul da cidade do Rio de Janeiro. A produção dos dados envolveu a realização de três grupos focais (todos realizados em novembro de 2017): um com seis docentes (P1, P2, P3, P4, P5 e P6), um com cinco gestores/técnicos (G1, G2, G3, G4 e G5) e um com oito alunos ( $A 1, A 2, A 3, A 4, A 5$, 
A6, A7 e A8) da escola. Entrevistamos cinco professoras e um professor, com média de idade de 42,5 anos, que lecionam as disciplinas de Biologia/Ciências (3), Inglês (1), Desenho Geométrico (1) e Química (1). No grupo dos gestores estiveram presentes a diretora da escola, duas técnicas em assuntos educacionais, um funcionário de apoio e uma integrante da equipe de direção. 0 grupo de estudantes entrevistados foi composto por 6 meninas e dois meninos, com média de idade de 16,25 anos, dos quais $75 \%$ cursava o primeiro ano do ensino médio. Residem na zona sul (4) e norte (2) da capital, além da baixada fluminense (2), evidenciando certa pluralidade de experiências de vida e condições socioeconômicas que enriqueceram o debate e que hoje são extensíveis ao ambiente escolar da instituição investigada.

O grupo focal foi utilizado por considerarmos uma metodologia frutífera para a construção de saberes no processo de investigação, fomentando a reflexão e o debate com base nas vivências dos sujeitos envolvidos. Na perspectiva de Lopes (2014), o grupo focal

(...) permite, ao pesquisador, compreender os processos de construção da realidade vivenciada por determinados grupos sociais, assim como compreender práticas cotidianas, atitudes e comportamentos prevalecentes no trabalho com alguns indivíduos que compartilham traços em comum, relevantes para o estudo e investigação do problema proposto (LOPES, 2014, p. 482).

Todos os grupos focais foram realizados na escola e registrados em áudio. As perguntas aos docentes giraram em torno das percepções do grupo sobre a relação entre a juventude e o consumo, se a mesma deve e vem sendo trabalhada na escola e os resultados obtidos; perguntamos, ainda, sobre a relação com o consumo do grupo na juventude e como percebem a influência dos atores sociais e das mídias nessa questão. Notou-se semelhança no discurso dos docentes de Biologia/Ciências, possivelmente pelas consequências dos impactos ambientais e sociais que a lógica consumista gera e que são temáticas curriculares do ensino destas disciplinas (lixo, poluição, degradação ambiental etc.). Fizemos as mesmas perguntas aos gestores (quatro mulheres e um homem), cuja média etária é de 44,8 anos e que estão na escola investigada há 18,8 anos (em média), possuindo as seguintes formações: química, artes visuais, engenharia civil, pedagogia e técnico-profissionalizante em andamento. As perguntas para os estudantes focalizaram suas percepções sobre o consumismo, seus sonhos de consumo, os sonhos que não envolvem consumo e se a escola promove atividades, em sala de aula ou fora dela, que problematizam essa relação.

Dentre os caminhos possíveis para se olhar a relação da juventude e o consumo, escolhemos aqui reportar apenas resultados que nos deem indícios de suas diferentes manifestações em contextos escolares. Sendo assim, analisamos 
falas dos participantes em diálogo com os referenciais teóricos adotados para entender o papel mediador exercido pela referida escola nesta relação. Os dados foram agrupados em categorias ou núcleos temáticos, que, segundo Gondim (2003, p.155), "dão suporte a linhas de argumentação, que revelam de que modo os participantes dos grupos focais se posicionam diante do tema, foco da discussão". Algumas categorias versam sobre a juventude e o consumo propriamente ditos e as possíveis interconexões entre esses termos; outras estão relacionadas à escola e potencialidades de atuação. São elas: o consumo em nossa sociedade atual; identidades juvenis e consumo; consumismo em debate na escola e consumo entre docentes, gestores e alunos. Decerto, não esgotamos a pluralidade de discursos e momentos significativos debatidos por alunos, professores, gestores e demais funcionários da escola em questão.

\title{
O CONSUMO EM NOSSA SOCIEDADE
}

Bauman (2008), Costa (2009), Oliveira e Tomazetti (2012), Fontenele (2017) e outros apontam a necessidade de se entender o consumo para compreendermos nossos desejos, ações e relações na contemporaneidade. Quando indagado por P4 se há determinado período de vida com maior grau de consumo que outro, P3 respondeu:

\begin{abstract}
Eu acho que não. Acho que ela começa assim... os pais consumistas ensinam seus filhos a serem consumistas e isso se prolonga. Até quando a pessoa chega até uma certa faixa de idade em que ela ganha mais, uma vez que viveu mais e conseguiu se qualificar melhor. Supondo, pegando essa faixa da população que tem acesso a isso né, nem todo mundo tem acesso a uma qualificação potencialmente melhor... vai ganhar mais depois e elas se tornam, elas compram mais entendeu? Elas começam a gastar com coisas que não gastavam antes. O problema todo se resume a: O que é preciso? Qual é a sua necessidade?
\end{abstract}

A fala deste docente corrobora a perspectiva de Costa (2009), ancorada em Bauman (2008), de que nossas necessidades na sociedade de consumidores são condicionadas pela lógica efêmera dos desejos, cheia de futilidades, celebridades e fortemente influenciadas pelo marketing e propagandas publicitárias (FONTENELE, 2017). Entretanto, as falas de P6 e G3, professora de inglês e servidora técnica da direção da escola, respectivamente, dialogam com um dado importante: o consumo atravessa a questão geracional (PAIS, 2003). O apelo ao consumo é tão forte que, independentemente de como a relação apareceu em sua juventude - com diferenças de ordem cultural, socioeconômica, escolar etc., as duas entrevistadas passaram pelo mesmo dilema. A fala de P6 explicita bem o problema: 
Eu sei que essa pesquisa é para adolescente, mas assim, eu acho que para todos nós, para mim é difícil pensar assim em faixa etária, eu acho que esse é o momento contemporâneo né? Bauman falou isso, como a gente vai comprando essa ideia do consumismo... Eu como mãe me vejo fazendo isso com o meu filho. Eu entro na loja de brinquedo, eu tô comprando pra mim, eu fico tão encantada... que eu tô criando nele necessidades. Agora quando eu chego é: o que você trouxe pra mim? Eu tô com dificuldade nisso.

\section{IDENTIDADES JUVENIS E CONSUMO}

Os discursos do senso comum acerca dos jovens (problemáticos, inquietos, questionadores) e os principais temas estudados no que se refere à juventude (violência, sexualidade, escolaridade, emprego) apresentam um fator em comum, presente em diversos momentos das entrevistas com docentes e gestores: é impossível analisar os jovens sem analisar suas formas de socialização Para compreendê-los, frente ao consumo ou não, se faz necessária uma reflexão sobre pertencimento de grupo e seus impactos nas identidades desses jovens. Desse modo, a questão do consumo se inicia na infância: crianças são diariamente bombardeadas com propagandas e peças publicitárias, ditando suas formas de vida e de ver o mundo. Duas falas de professores (P2 e P4, das disciplinas de desenho geométrico e biologia, respectivamente) explicitam essa questão:

Eu acho que é herdado, que essa questão não surge na adolescência. Eu acho que o consumo é herdado... herdado até da própria família, não dizendo "não" e compensando algumas coisas com presentes, vai alimentando isso até chegar na adolescência, onde isso já tá internalizado. E a mídia, o grupo, tudo isso fala muito alto pro adolescente né?

Acho que essa fase da vida é uma fase que está normalmente associada a um consumo alto, né? $E$ que isso atualmente é sinônimo de modernidade. Até assisti uma vez um cara falando que a gente vive numa sociedade adolescêntrica, um psicólogo da UFMG que empurra a criança para adolescência mais cedo e tira da adolescência mais tarde porque esse é o período de maior consumo. Então acho que é o período que essa questão do consumo é muito forte... tem uma coisa de status né, de fazer parte do grupo através do consumo, então acho que isso aparece um pouco...

A fala acima fortalece o argumento de Bourdieu (1983) e outros autores sobre a classificação etária não corresponder a uma classificação social definida. Desse modo, entender juventude a partir do fator idade não é epistemologicamente potente. É imperativo entendê-la enquanto uma condição social, fortemente imbricada com os conflitos do viver contemporâneo e líquido (BAUMAN, 2008). 
DOI: $10.12957 /$ e-mosaicos.2018.34194

\section{CONSUMISMO EM DEBATE NA ESCOLA}

As iniciativas na escola que abordam a questão do consumo na sociedade contemporânea apareceram na fala de alunos, professores e gestores, mas, curiosamente, não há consenso nas afirmações. Ao passo que professores, como P5 e P6, disseram desconhecer ações pedagógicas que discutam o tema na escola, assim como G3, A2 e A1, a fala de P1, uma das professoras de Biologia, explicita o oposto:

Então, eu quero falar... o que eu vejo aqui na escola, aqui nos alunos, no nosso grupo de alunos que eu trabalho [ensino médio], eu não sei se é por conta da formação da escola, que vem fazendo essa reflexão sobre consumo em várias disciplinas, eu já vejo eles trazendo uma contraposição a isso, entendeu, no discurso deles. Então, quando eu chego no terceiro ano, que a gente tá discutindo Ecologia, eu apresento o vídeo da "História das Coisas", é uma coisa que eles já viram. Eles falam "pô, professora, traz coisas novas...", "de novo, professora?" ou "ah, a gente já viu no nono [ano]". Acho que é uma coisa que já viram dentro da escola, eu acho que eles já tão, não sei se em todas as escolas, mas pelo menos aqui no [nome da escola], eu acho que essa é uma preocupação de vários professores e muitos deles já estão com sua posição marcada. [Segundo ela, os alunos dizem] "não, por que a questão do consumo, que alimenta o capitalismo...

A fala dessa professora e outras como "eu nunca trabalhei e desconheço quem trabalhe consumismo entre os meus colegas da química, mas sei que de vez em quando acontece um trabalho de artes visuais sobre lixo", frase dita por P6, ilustram, a princípio, certa falta de comunicação intraescolar acerca de diferentes iniciativas pedagógicas realizadas pelos docentes. Podem também apontar para uma pluralidade de entendimentos sobre o que é "trabalhar consumo". No entanto, outra forma de olhar para a afirmação da professora é justamente conhecendo o perfil da escola em questão. Nela, há descentralização em decisões e ações entre cada um dos dezoito setores curriculares. Desse modo, metodologias pedagógicas a serem utilizadas, dentre outras coisas, são debatidas pelos professores do setor (ciências biológicas, história, língua inglesa etc.), o que de um lado, garante certa autonomia aos docentes, mas, de outro, dificulta a veiculação dessas abordagens, projetos e iniciativas realizadas dentro e fora de sala de aula.

\section{O CONSUMO ENTRE DOCENTES, GESTORES E ALUNOS}

(...) Ah, eu sei que a minha mãe me ama, tipo assim, faz tudo por mim e tal, mas ela às vezes compra umas coisas que eu fico tipo...

\footnotetext{
${ }^{8}$ Célebre vídeo The Story of Stuff, que baseou o livro A História Das Coisas: da Natureza Ao Lixo, o Que Acontece Com Tudo Que Consumimos (2011), de Anne Leonard.
} 
que? Ela vem me dar umas roupas, umas coisas que ela compra na rua e eu fico assim: mãe, eu não tava precisando disso, daí ela fica falando "mas filha, eu comprei porque achei que você ia gostar"... daí eu não tenho muito o que fazer né? Tenho que ficar com aquilo mesmo sem querer pra minha mãe não ficar, sei lá, chateada comigo.

As falas de P3 sobre as origens do hábito de consumir pelos sujeitos e de A5, uma estudante do primeiro ano que mora num bairro nobre da capital fluminense, corroboram a perspectiva de Costa (2009), Oliveira e Tomazetti (2012), Bastos et al (2015) e também discursos observados nos próprios docentes e gestores investigados e evidenciam a importância dos laços afetivos (no caso, família) na questão do consumo. Nossa(s) identidade(s), gostos, medos, sonhos e perspectivas estão relacionados diretamente ao que nos cerca, posto que assumimos essa identidade na diferença com o outro. Amigos, família e pertencer a um grupo são meios importantes de aceitação, convívio social e exercício da construção identitária dos jovens, expondo nosso desejo de aceitação perante a sociedade, desde que estejamos enquadrados às normas vigentes. A construção das identidades juvenis é vista por Bauman (2008) e Bourdieu (1983) como flexível, isto é, o jovem assume diferentes identidades em diferentes contextos ao longo da vida, corroborando a tese de que juventude é uma construção social.

\section{CONSIDERAÇõES FinAIS}

Cotejando percepções dos próprios jovens com narrativas de professores e gestores sobre sua relação com o consumo hoje e quando eram jovens, notamos que a questão geracional evidencia apenas uma maior oferta de produtos e crescente ocupação de nichos de mercado pelo setor industrial nos últimos 30 anos. Docentes e gestores tinham desejos e sonhos de consumo similares aos dos jovens de hoje, diferindo apenas nos objetos de desejo, já que existe, hoje, maior oferta de roupas, utensílios, objetos e produtos tecnológicos - criando uma demanda de bens com obsolescência pré-definida e levando a uma (in)constante busca por novos produtos. Desse modo, perguntamos: o quanto a problemática do consumo é uma questão do jovem e não da própria sociedade? Por que os adultos insistem em rotular os jovens como consumistas, sendo que os mesmos estão imersos na lógica da sociedade de consumidores? Por que as ações da escola, de forma geral, não são discutidas com os estudantes?

Em diálogo com Dayrell (2003), arriscamos afirmar que as respostas a essas questões têm relação com a dificuldade de se considerar os jovens como "sujeitos sociais que, como tais, constroem um determinado modo de ser jovem" (p. 40), superando concepções negativas voltadas para uma suposta transitoriedade e incompletude dos jovens. Essa visão, muito comum nas escolas, é geradora de

\footnotetext{
${ }^{9}$ Grifo nosso.
} 
conflitos e não contribuiu para a construção de pedagogias e políticas voltadas para os jovens enquanto "sujeitos sociais que constroem um determinado modo de ser jovem baseados em seu cotidiano" (DAYRELL, 2003, p. 41). Vale ressaltar que falar de juventude no Brasil hoje é considerar mais de 51 milhões de brasileiros (IBGE, 2010) com seus sonhos, desejos, conflitos, conquistas e histórias.

Segundo dados do Fundo de População das Nações Unidas (UNFPA) em 2014, estima-se que existam hoje mais de 1,8 bilhão de pessoas no mundo com idade entre 10 e 24 anos, formando a maior população de jovens (15 a 24 anos) e adolescentes (10 a 19 anos) de todos os tempos, do qual os países em desenvolvimento concentram $85 \%$ desse contingente. Esses jovens podem contribuir diretamente no desenvolvimento social e econômico de cada país, desde que sejam dadas condições educacionais, de segurança e qualidade de vida que permitam esse avanço. É fundamental, também, que a juventude passe a ser entendida como uma condição social e histórica, com profundas diferenças em relação aos diferentes pertencimentos dos indivíduos que compõem este grupo etário cuja caracterização, como afirmamos no início deste artigo, pode variar no tempo e no espaço.

Em outro momento, afirmarmos que "ao dar voz aos jovens ${ }^{10}$, ou, dizendo de outra forma, ao abrimos um canal de escuta para estes sujeitos, podemos fazer emergir importantes questionamentos sobre seus próprios hábitos de consumo" (BASTOS et al, 2015, p.10). Entender a relação dessa parcela da população com o consumo se torna importante para a discussão de políticas públicas voltadas à juventude $^{11}$ que os contemplem como sujeitos singulares e históricos que interpretam e dão sentido ao mundo (DAYRELL, 2003).

Em agosto de 2018 serão realizadas entrevistas com docentes, alunos e gestores de uma escola estadual que atende a estudantes do ensino regular, do curso de magistério e da Educação de Jovens e Adultos. Os dados produzidos serão analisados em conjunto com os da escola pública federal, em busca de padrões e/ou de diferenças relacionadas aos grupos investigados. Os grupos focais com docentes, gestores, técnicos e estudantes da escola federal trouxeram para o grupo uma gama de reflexões sobre a relação entre juventude e consumo. A questão identitária via consumo esteve presente na fala de alguns deles, reiterando a pluralidade de caminhos trilhados pelos jovens em busca de afirmação pessoal. Nesse sentido, defendemos, com Dayrell (2003) a construção de uma concepção de juventude na perspectiva da diferença e da diversidade, o que implica "considerá-la não mais presa a critérios rígidos, mas sim como parte de um processo de crescimento mais totalizante, que ganha contornos específicos no conjunto das experiências vivenciadas pelos indivíduos no seu contexto social" (p.42).

\footnotetext{
10 Grifo nosso.

${ }^{11}$ Como o Estatuto da Juventude (Lei no 12.852/2013) e o projeto de lei que visa implementar o Plano Nacional da Juventude (PL 4.530/2004), até hoje em tramitação na Câmara dos Deputados.
} 
DOI: $10.12957 / \mathrm{e}-\mathrm{mosaicos} .2018 .34194$

A partir deste estudo, defendemos que para compreender a complexa e multifacetada relação entre a juventude e o consumo, é fundamental pensar os jovens como sujeitos sociais e históricos, estranhos a nós pois que são diferentes, no sentido estrito do termo. Afinal, se é "a experiência, e não a verdade, que dá sentido à educação" (LARROSA e KOHAN, 2017, p.5), concluímos com estes autores que educar é "uma experiência que nos permite liberar-nos de certas verdades, de modo a deixarmos de ser o que somos para ser outra coisa, diferente do que vimos sendo" (idem).

\section{REFERÊNCIAS}

ABRAMOVAY, M.; CASTRO, M. G. Juventude, juventudes: o que une e o que separa. Brasília, UNESCO, 2006 744p. Disponível em: <

http://unesdoc.unesco.org/images/0014/001468/146857porb.pdf>. Acesso em 5 jul. 2018.

ABRAMOVAY, M.; CASTRO, M. G. Ser jovem no brasil hoje: políticas e perfis da juventude brasileira. Cadernos Adenauer, n.1, v.16. 2015. Disponível em: < http://www.kas.de/wf/doc/16488-1442-5-30.pdf>. Acesso em 10 abr. 2018.

BASTOS, C. B. et al. 'Sonhos de Consumo': uma pesquisa com jovens de duas escolas públicas do município do Rio de Janeiro. In: ANAIS DO VIII Encontro PESQUISA EM EDUCAÇÃO AMBIENTAL (VIII EPEA). Rio de Janeiro, 2015. Disponível em: <http://epea.tmp.br/epea2015_anais/pdfs/plenary/98.pdf>. Acesso em 02 abr. 2018.

BAUMAN, Z. Vida para consumo: a transformação das pessoas em mercadoria. Rio de Janeiro: Jorge Zahar Ed., 2008.

BOURDIEU, Pierre. A juventude é apenas uma palavra. Questões de sociologia. 1983. Rio de Janeiro: Marco Zero. P. 112-121.

BRASIL. Política Nacional de Juventude: diretrizes e perspectivas. São Paulo: Conselho Nacional de Juventude; Fundação Friedrich Ebert. 140p. 2006. Disponível em: <http://library.fes.de/pdf-files/bueros/brasilien/05611.pdf>. Acesso em 02 mai. 2018.

COSTA, M. V. Educar-se na Sociedade de Consumidores. In: COSTA, Marisa Vorraber (org.) A Educação na Cultura da Mídia e do Consumo. Rio de Janeiro: Lamparina, 2009.

COSTA, M. V. Há estranhos nas escolas. In: COSTA, Marisa Vorraber (org.) $A$ Educação na Cultura da Mídia e do Consumo. Rio de Janeiro: Lamparina, 2009. p. 90-92. 
DAYRELL, J. O jovem como sujeito social. Revista Brasileira de Educação, n. 24, set.dez. 2003, p. 40-52. Disponível em:

<http://www.scielo.br/pdf/rbedu/n24/n24a04.pdf>. Acesso em: 15 mar. 2018.

ESTEVES, L. C. G.; ABRAMOVAY, M. Juventude, juventudes: pelos outros e por elas mesmas. In: ABRAMOVAY, M.; ANDRADE, E. R.; ESTEVES, L. C. (Orgs.) Juventudes: outros olhares sobre a diversidade. Brasília: Ministério da Educação, Secretaria de Educação Continuada, Alfabetização e Diversidade; UNESCO. 2007. p.19-54. Disponível em: <http://unesdoc.unesco.org/images/0015/001545/154580por.pdf>. Acesso em 14 mai. 2018.

FONTENELE, I. A. Cultura do consumo: fundamentos e formas contemporâneas. Rio de Janeiro, FGV Editora, 2017.

FUNDO DE POPULAÇÃO DA ORGANIZAÇÃO DAS NAÇÕES UNIDAS (UNFPA). Estado de la población mundial 2014 - El poder de 1.800 millones: los adolescentes, los jóvenes y la transformación del futuro. Disponível em: < https://www.unfpa.org/sites/default/files/pubpdf/SWOP2014\%20Report\%20Web\%20Spanish.pdf>. Acesso em 10 mai. 2018.

GAWRYSZEWSKI, B.; MOTTA, V. C.; PUTZKE, C. K. Gestão privada de escolas públicas da Educação Básica: um novo mercado sob a tutela do Estado. Práxis Educativa, n.3, v.12, set.-dez. 2017, p.728-748. Disponível em: < http://www.revistas2.uepg.br/index.php/praxiseducativa/article/view/9413/5564>. Acesso em: 14 mai. 2018.

GONDIM, S. M. G. Grupos focais como técnica de investigação qualitativa: desafios metodológicos. Paidéia, 2003, n.12, v.24, 149-161. Disponível em: <http://www.redalyc.org/html/3054/305425350004>. Acesso em 5 jul. 2018.

INSTITUTO BRASILEIRO DE GEOGRAFIA E ESTATÍSTICA (IBGE). Censo 2010. Disponível em: <https://censo2010.ibge.gov.br>. Acesso em 10 abr. 2018.

LARROSA, J. e KOHAN, W. Elogio da escola: o desafio de pensar uma forma sem função. In: LARROSA, Jorge (org.): Elogio da Escola. Belo Horizonte, Autêntica Editora, 2017.

LEHER, R.; VITTORIA, P.; MOTTA, V. C. Educação e mercantilização em meio à tormenta político-econômica do Brasil. Germinal: Marxismo e Educação em debate, n.1, v.9, abr. 2017, p.14-24. Disponível em: < https://portalseer.ufba.br/index.php/revistagerminal/article/view/21792/14337>. Acesso em: 9 jul. 2018.

LOPES, B. E. M. Grupo focal na pesquisa em ciências sociais e humanas. Revista Educação e Políticas em Debate, n.2, v.3, ago./dez. 2014. Disponível em: 
$<$ http://www.seer.ufu.br/index.php/revistaeducaopoliticas/article/viewFile/30290/165 45>. Acesso em 5 jul. 2018.

OLIVEIRA, A. M.; TOMAZETTI, E. Quando a sociedade de consumidores vai à escola: um ensaio sobre a condição juvenil no Ensino Médio. Educar em Revista, Curitiba, n.44, p.181-200, jun. 2012. Disponível em: < http://www.scielo.br/pdf/er/n44/n44a12.pdf>. Acesso em 14 mai. 2018.

PAIS, J. M. Culturas juvenis. Lisboa: Imprensa Nacional - Casa da Moeda, 2003.

ROCHA, E.; PEREIRA, C. (orgs.). Juventude e consumo: um estudo sobre a comunicação na cultura contemporânea. Rio de Janeiro: Mauad X, 2009.

SAEZ, E. S.; SANTIAGO, G.; ZACCHI, J. M. (orgs.) Censo gife 2016. São Paulo: GIFE, 2017. 256p. Disponível em: <https://sinapse.gife.org.br/download/censo-gife2016>. Acesso em 09 jul. 2018.

Recebido em 15 de maio de 2018 Aceito em 29 de junho de 2018 